\title{
Pu-erh tea: Fermentative process as a potentialized of sensory aspects and bioactive
}

\section{profile - a review}

Chá Pu-erh: Processo fermentativo como potencializador de aspectos sensoriais e perfil bioativo uma revisão

Té Pu-erh: Proceso fermentativo como potencialización de aspectos sensoriales y perfil bioactivo una revisión

Rafaela Julyana Barboza Devos ORCID: https://orcid.org/0000-0003-3734-749X University of Passo Fundo, Brazil

E-mail: rafaela.devosb@gmail.com

Cristina de Araújo Barth

ORCID: https://orcid.org/0000-0003-1677-293X

University of Passo Fundo, Brazil

E-mail: engcristinabarth@gmail.com

Aline Dettmer

ORCID: https://orcid.org/0000-0002-6578-9159

University of Passo Fundo, Brazil

E-mail: alinedettmer@upf.br

Telma Elita Bertolin

ORCID: https://orcid.org/0000-0002-8944-3398

University of Passo Fundo, Brazil

E-mail: telma@upf.br

Luciane Maria Colla

ORCID: https://orcid.org/0000-0001-9745-4452

University of Passo Fundo, Brazil

E-mail:1mcolla@upf.br

\begin{abstract}
$\mathrm{Pu}$-erh is a fermented Chinese tea with characteristics of mild, woody flavor and dark red color. The preparation of the tea starts from leaves of Camellia sinensis in natura that undergo a drying in the sun. Its classification is given in two categories: a raw tea similar to green tea and a matured tea that is fermented. Matured tea has a higher market value due to the processes involved in manufacturing, especially in terms of aging. Pu-erh has numerous benefits for human health, which are closely related to the bioactive profile of the main chemical components of tea, being polyphenols, theabrownins, flavonols, polysaccharides, amino acids and alkaloids. The increasing introduction of Pu-erh tea in the diet of consumers results in the need to explore information associated with consumption through analysis of the available literature, addressing current scientific evidence. Therefore, the present review sought to elucidate the fermentative process of Pu-erh tea production, its chemical composition, its sensory aspects and health benefits.
\end{abstract}

Keywords: Bioactive profile; Camellia sinensis; Fermentative process; Health; Sensory aspects.

\section{Resumo}

Pu-erh é um chá chinês fermentado com características de sabor amadeirado suave e cor vermelha escura. O preparo do chá parte de folhas de Camellia sinensis in natura que passam por uma secagem ao sol. Sua classificação é dada em duas categorias: um chá cru semelhante ao chá verde e um chá maturado que é fermentado. O chá maturado tem maior valor de mercado devido aos processos de fabricação, principalmente no que diz respeito ao envelhecimento. $\mathrm{O}$ pu-erh apresenta inúmeros benefícios para a saúde humana, os quais estão intimamente relacionados ao perfil bioativo dos principais componentes químicos do chá, sendo polifenóis, theabrownins, flavonóis, polissacarídeos, aminoácidos e alcalóides. A crescente introdução do chá Pu-erh na dieta alimentar dos consumidores resulta na necessidade de explorar informações associadas ao consumo por meio da análise da literatura disponível, abordando as evidências científicas atuais. Portanto, a presente revisão buscou elucidar o processo fermentativo de produção do chá Pu-erh, sua composição química, seus aspectos sensoriais e benefícios à saúde.

Palavras-chave: Perfil bioativo; Camellia sinensis; Processo fermentativo; Saúde; Aspectos sensoriais. 


\section{Resumen}

Pu-erh es un té chino fermentado con características de sabor suave a madera y color rojo oscuro. La preparación del té parte de hojas de Camellia sinensis in natura que se someten a un secado al sol. Su clasificación se da en dos categorías: un té crudo similar al té verde y un té maduro que se fermenta. El té madurado tiene un mayor valor de mercado debido a los procesos involucrados en la fabricación, especialmente en términos de envejecimiento. Pu-erh tiene numerosos beneficios para la salud humana, los cuales están estrechamente relacionados con el perfil bioactivo de los principales componentes químicos del té, siendo los polifenoles, theabrowninas, flavonoles, polisacáridos, aminoácidos y alcaloides. La creciente introducción del té Pu-erh en la dieta de los consumidores da como resultado la necesidad de explorar la información asociada con el consumo a través del análisis de la literatura disponible, abordando la evidencia científica actual. Por lo tanto, la presente revisión buscó dilucidar el proceso fermentativo de la producción de té Puerh, su composición química, sus aspectos sensoriales y beneficios para la salud.

Palabras clave: Perfil bioactivo; Camellia sinensis; Proceso fermentativo; Salud; Aspectos sensoriales.

\section{Introduction}

The second most popular drink in the world is tea, mainly due to its numerous health benefits. Currently drinking tea has become a habit or even a lifestyle for many people, being served at all meals or at leisure (Shao et al., 2020). In China, tea can be classified into at least six types based on its degree of fermentation (Figure 1), including unfermented tea (green and white tea), slightly fermented tea (yellow tea), semi fermented tea (oolong tea), fully fermented tea (black tea) and post-fermented tea (dark tea) (Zhou et al., 2020a).

Figure 1 - Tea types and its processing.

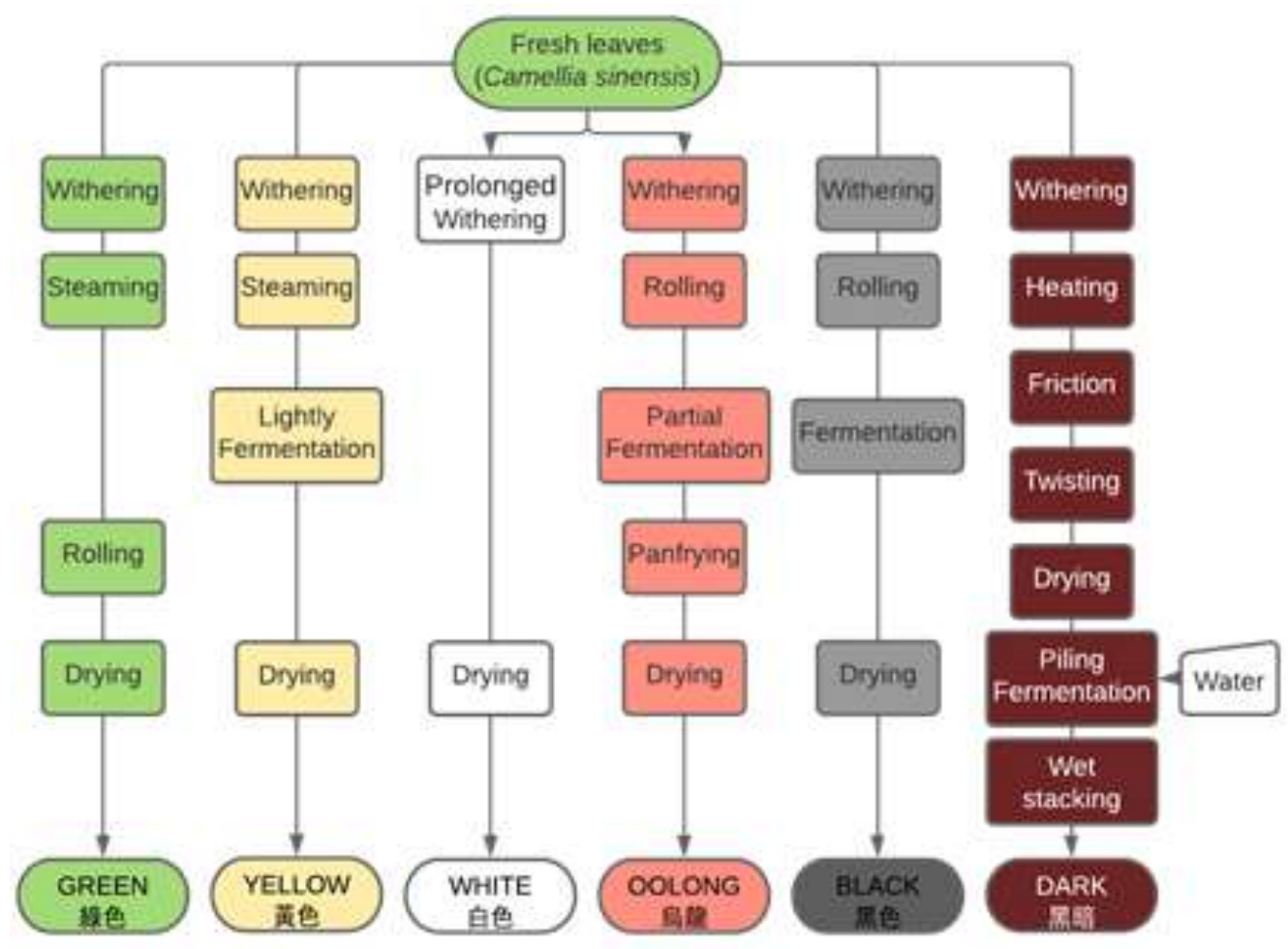

Source: Authors (2021).

As seen in Figure 1, in the processing of dark tea, the fermentation step takes place in a pile and due to the participation of microorganisms in this step and the storage condition, $\mathrm{Pu}$-erh tea can be considered a product originating from the postfermentation process (Zhou et al., 2020a). Pu-erh tea, grown in southwest China (Yunnan province), is produced by microorganisms in a solid-state fermentation under high humidity, from sun-dried green tea, produced from Camellia sinensis (Long et al., 2020). According to the processing technology Pu-erh tea can be classified as raw or matured (ripened). Raw tea is 
produced from sun-dried green tea using an autoclave and compression process. Ripened tea is produced in the same way as raw tea, but fermentation takes place in a short and intense time, with a stack fermentation that lasts from one to two months (Cao et al., 2021). In addition to these classifications, it can also be found in its loose or compressed form (snapshot) as shown in Figure 2 (Lee; Foo, 2013).

Figure 2 - Presentation forms of Pu- erh tea: (1) loose form and (2) compressed.
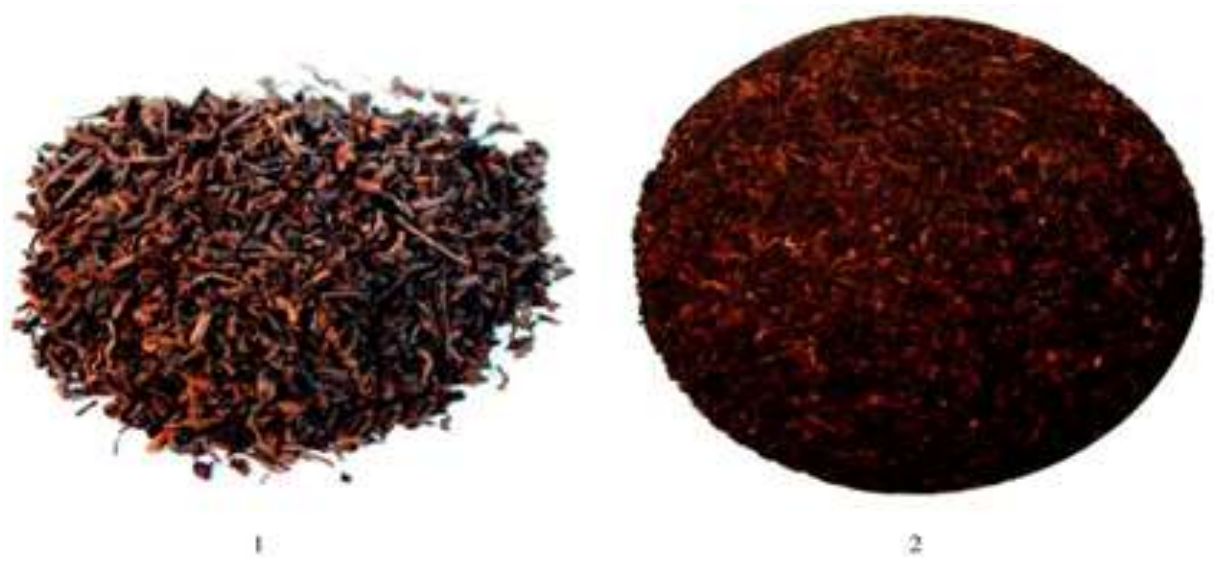

Source: Lv et al., 2013b.

The history of the Camellia sinensis plant with people from different provinces of China (Yunnan, Bulang (Blang), Wa, Akha (Hani), Lahu, Yao, Hmong (Miao), Jinuo, De'ang, Dai and Han) is reported for many years. These people believed that the plant was left by the Prime Minister of Shu, Zhugeliang, during the Three Kingdoms period (AC 220 to 280). Every year there was a celebration to harvest the leaves and nowadays its consumption has become a social practice related to well-being and alertness. The processing of Pu-erh tea follows an ancestral methodology from eastern China, known as Gong fu cha dao ('tea form' with 'effort/skill'), which aims to release the compounds responsible for aroma, flavor, color and ideal physiological properties of tea. However, due to the expansion in the market, the amount of leaf used and the water temperature in the infusions are adapted according to the consumers preference (Lee; Foo, 2013).

In addition to the use of Camellia sinensis, Pu-erh tea can be obtained from other leaves and variations. Pu-erh tea made from Gushu, which refers to the ancient tea trees, is prepared from old cultivated trees, which are referred to as cultivated $\mathrm{Pu}$ erh. The market value of tea varies according to the age of the tree in which the leaves were obtained, with high added value (Choi et al., 2018). Fermented Zijuan Pu-erh tea is produced from Camellia sinensis var. Kitamura. Its leaves are processed into Zijuan green tea by various procedures, including fixing, rolling and drying in the sun for several days. Its benefit can increase through proper wetting and solid-state fermentation. The fermented Zijuan Pu-erh tea is brown and its liqueur is thick and bright red, with a rich flavor without notes of bitterness (Fan et al., 2013).

Pu-erh tea is characterized by its distinctive and smooth aroma and dark red color (Wu et al., 2020). These sensory aspects are achieved after the fermentation of the tea, since the infusion of the raw material has an astringent flavor and yellow color. This flavor modification is related to microbial activity and chemical metabolites in tea (Zhao et al., 2019). Studies demonstrate the presence of polyphenols, theabrownins, flavonols, polysaccharides, alkaloids and amino acids (Huang et al., 2019b, Long et al., 2020), which are linked to the health benefits related to tea consumption (Ma et al., 2021).

The increase in the use of Pu-erh tea in salads, vegetables and other snacks/foods has been documented for years (Lee; Foo, 2013), however its increasing introduction into the diet results in the need to better understand its fermentation process, 
sensory aspects and bioactive activity with beneficial health effects, which was the aim of this study.

\section{Methodology}

\subsection{Bibliographic survey}

The bibliographic survey related to the term Pu-erh was based on a search of terms in the Scopus database. Through the only term "Pu-erh" established in the title, abstract and keywords, the survey returned a total of 357 results: 324 research articles, 13 review articles, 11 conference papers and 6 books chapters. Of these, the conference papers and book chapters were excluded. The investigation of studies used the Bibliometrix library for the R software (R Core Team, 2017) for the bibliometric analysis and alongside it, it was pointed out which were the main topics and trends related to the central theme, present in Figure 3 . The topics covered in this review were selected from the topics most cited in the article titles or in a set of words that refer to the central theme.

Figure 3 - Cloud of words generated from the term "Pu-erh" based on world scientific production.

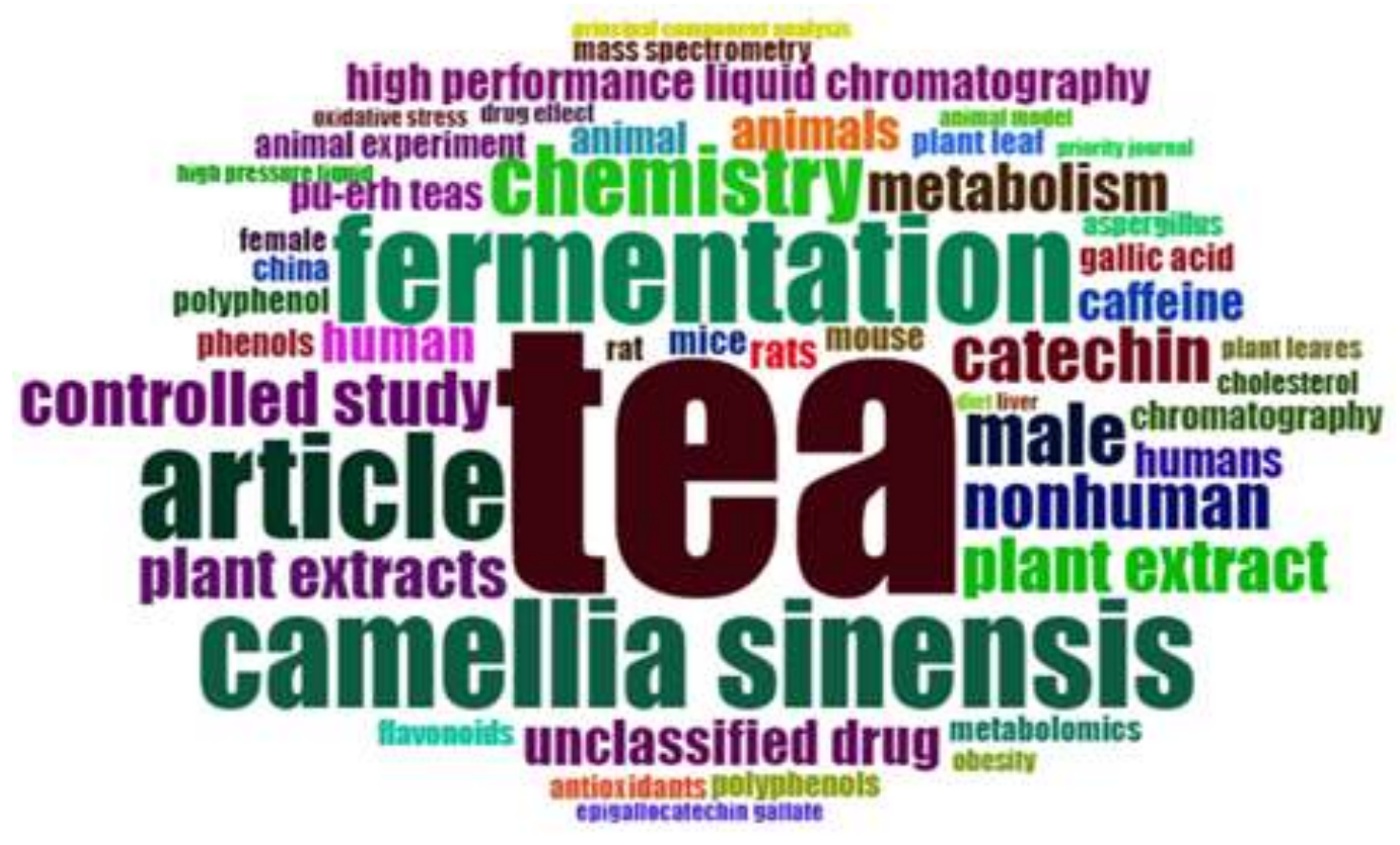

Source: Bibliometrix library.

There has been a growing trend in publications on the subject in the past 11 years. The largest number of publications by country comes from China with 229 publications, followed by Taiwan and the United States, both with 28 publications. The study area with the largest number of documents are agricultural and biological sciences with 190 publications, followed by chemistry, biochemistry, genetics and molecular biology and pharmacology, toxicology and pharmaceuticals with 120,81 and 62 publications, respectively. A filtering was carried out selecting only research articles and review articles published from the year 2010, returning 295 results.

The frequently cited terms were related to the fermentation of $\mathrm{Pu}$-erh tea and its production from Camellia sinensis, as well as a considerable number of terms related to the chemical structure of tea, controlled studies in vitro (animals and humans), plant extract and metabolism of bioactive compounds (catechins, phenols, caffeine, flavonoids, among others). Quantification methods, such as high performance liquid chromatography and mass spectroscopy were also mentioned. The filtering of the 
articles was done considering those that presented in the title, abstract and keywords the fermentative aspects of Pu-erh tea (86 results), its chemical structure (78 results), sensory aspects (21 results), metabolism ( 25 results), health benefits related to the consumption ( 75 results) and bioactive profile ( 26 results). The abstracts of the filtered articles were read and those that fit the review proposal were selected and referenced in the present study.

\section{Results and Discussion}

\subsection{Fermentative process}

The processing of Pu-erh tea involves several steps. Initially the harvested leaves are placed for aeration (withered), followed by heating, friction, twisting and drying in the sun. Subsequently water is added to the leaves and they are stacked for fermentation (Haas et al., 2013). Fermentation is one of the main processes by which tea is subjected, with a crushing of the leaves in order to promote enzymatic oxidation and the polymerization of the polyphenols present in the tea into oligomeric and polymeric polyphenols (Yang et al., 2011). The wet stacking of the leaves for maturation of the tea is used to accelerate the process, however it is favorable to fungal contamination (Sedova et al., 2018). The leaves of the mature tea are fermented for months and then pressed, while the leaves of the raw tea are subjected to the press initially and then arranged for fermentation (room temperature) for years (Roda et al., 2019). This process depends on microbial communities and enzymes that are involved in the metabolism of phenolic compounds in Pu-erh tea fermentation (Zhao et al., 2019).

The tea leaves contain approximately 385 strains of fungi that participate in the fermentation process, these being predominantly of the genus Aspergillus and the species Aspergillus niger (Armstrong et al., 2020). However, the fungi present in raw and matured $\mathrm{Pu}$ - erh tea are distinct, due to the influence of manufacturing processes on microbial structures. The genus Aspergillus, Cladosporium, Eurotium, Fusarium, Rhodotorula, Acremonium and Penicillium are the largest constituents of fungal communities in raw Pu-erh tea samples, while ripened tea consists mainly of the genus Aspergillus, Blastobotrys, Rasamsonia and Thermomyces (Xue et al., 2020). Matured Pu-erh tea has more fungal colonizations than raw tea, more precisely 16 and 8 genus, respectively (Zhao et al., 2010).

Solid state fermentation is considered to be the most important stage in the processing of $\mathrm{Pu}$-erh tea as it allows the achievement of unique flavor and aroma characteristics in the tea infusion (Long et al., 2020). In fermentation the formation and flavor of Pu-erh tea occurs due to the formation of volatile compounds such as hydrocarbons, alcohols, ketones, esters, methoxyphenolic compounds, aldehydes, phenolic compounds, nitrogen compounds and lactone compounds. Aspergillus is considered a functional microorganism in the fermentation process because it is present in the formation pathways of different flavor compounds such as theabrownin, methoxyphenolic, alcohol and carvone. In addition to this, the genus Bacillus, Rasamsonia, Lichtheimia and Debaryomyces stand out for aromatic production (Li et al., 2018).

During ripening many dominant fungi are involved in enzymatic reactions of the main chemical components of tea (Armstrong et al., 2020). These microorganisms are considered beneficial as they increase the content of theabrownins, vitamins and reduce the content of caffeine present (Li et al., 2018). Microorganisms beneficial to the product as Lactobacillus, Aspergillus, Lactococcus and Penicillium are found in Pu-erh tea, being more abundant in the matured sample compared to raw tea (Xue et al., 2020).

The fermentation process can occur naturally or by inoculation with artificial fungus. The first option requires a longer fermentation time (around weeks) and the second is able to confer desired and characteristic sensory aspects of the product, such as color, flavor and aroma, in a reduced time. In addition to the time of the process, the selection of microorganisms used for the post-fermentative deserves attention, as they are used in the production of bioactive compounds (Lv et al., 2013a). Still, aspects such as tea origin and fermentation preparation also affect the composition and biological activity of Pu-erh tea (Roda et al., 
2019). Thus it can be considered that the fermentative process of Pu-erh tea is an enhancer of the sensory aspects characteristic of the product, as well as its bioactive profile.

The main source of colonization of $\mathrm{Pu}$-erh tea fungi is the production environment, and production time is a factor that implies the content of microorganisms. The longer the processing time, the greater the chance of the product coming into contact with external fungi, a fact that justifies the high colonization in mature tea when compared to raw tea. In this sense, the presence of Cladosporium cladosporioider in raw Pu-erh tea samples may be related to contamination by air or internal environments. Another source of colonization is the raw material, since low quality Pu-erh tea samples are produced from old leaves that are more susceptible to airborne fungal contamination and fungal diseases. Pu-erh tea produced from old leaves is termed low grade, which can present undesirable parasitic fungi as Eutypella vitis and Septogloeum mori (Zhao et al., 2010).

The genus Aspergillus, Cladosporium, Penicillium and Trichoderma can also be undesirable because they can be toxic due to their ability to produce mycotoxins and cause food spoilage (Zhao et al., 2010). Mycotoxins are secondary metabolites produced by toxigenic fungi in adequate conditions of humidity and temperature for development. These contaminants can contaminate a variety of crops at all stages of production, from planting to storage. Inadequate agricultural management, water stress in the pre-harvest period, the use of inefficient packaging and inappropriate transport are examples of conditions that favor fungal growth and risk of mycotoxin contamination (Sedova et al., 2018). However, fungal development is not indicative of mycotoxin production, since despite the growth of fungi there may be no detection of mycotoxins in some samples, when the ideal conditions of production and storage are respected. Just as the production of mycotoxins during processing can be evaluated in samples with low fungal contamination (Pakshir et al., 2020).

The Aspergillus fumigatus fungus is considered undesirable because it does not have beneficial effects on the fermentative process of tea, it has toxic effects on health (liver), in addition to being thermotolerant to thermophilic mold, characteristic of decomposing organic matter (Haas et al., 2013). Although the Aspergillus fungus is related to several functions in the fermentation process of Pu-erh tea, such as for enzymatic production, of lovastatin, puerins and teadenol, conversion of polyphenols, degradation of caffeine, formation of bioactive compounds and flavor producer, this fungus is a producer of mycotoxin ochratoxin A (OTA) (Ma et al., 2021). OTA was discovered in 1965 in South Africa, being a potent nephrotoxin that causes renal and liver dysfunction in animals and humans (Apeh et al., 2021, Ferreira et al., 2021), mainly produced by A. ochraceus. In addition, aflatoxins are also considered to be potent health hazards as they have mutagenic, carcinogenic, teratogenic and immunosuppressive effects, causing chronic diseases such as liver cancer (Pakshir et al., 2020). Produced mainly by Aspergillus flavus and A. parasiticus in wet and hot conditions (Haas et al., 2013). The high occurrence of aflatoxin in China means that the determination of this contaminant is evaluated in $\mathrm{Pu}$-erh tea samples in several studies, however the screening of a wide range of mycotoxins such as aflatoxins, ochratoxins, zearalenone, fumonisins, T-2 toxin and deoxynivalenol is checked (Bogdanova et al., 2020, Pakshir et al., 2020, Haas et al., 2013).

The solubility of some mycotoxins in water (aflatoxins, OTA, fumonisins, zearalenone, T-2 toxin and deoxynivalenol) represents a danger to tea, as contamination can be extracted from the matrix by water (Sedova et al., 2018). In addition, the thermal stability of mycotoxins must also be considered, since contaminants resistant to high temperatures are not degraded when exposed to thermal processing (Pakshir et al., 2020). Ochratoxins (OTA), fumonisins, aflatoxins (AFs), deoxynivalenol (DON) and zearalenone (ZEA) are the main mycotoxins present in Pu-erh tea and the health effects caused are shown in Table 1. 
Table 1 - Main mycotoxins present in Pu-erh tea.

\begin{tabular}{ccc}
\hline $\begin{array}{c}\text { Identified } \\
\text { microorganisms }\end{array}$ & Mycotoxin & Related health problems
\end{tabular}

\begin{tabular}{lll}
\hline Aspergillus & OTA & $\begin{array}{l}\text { potentially carcinogenic nephrotoxin by IARC } \\
\text { (group 2B) }\end{array}$ \\
& $\begin{array}{l}\text { Apeh et al., 2021 } \\
\text { causes renal and liver dysfunction, urothelial } \\
\text { cancer of the urinary tract }\end{array}$ & \\
& Ferreira et al., 2021
\end{tabular}

\begin{tabular}{lll}
\hline A. fumigatus & OTA & invasive infections in immunosuppressed Haas et al., 2013 \\
A. ochraceus & patients, fungal infection in neutropenic \\
A. niger & patients
\end{tabular}

\begin{tabular}{lll}
\hline Penicillium & OTA & renal toxic effect \\
Haas et al., 2013
\end{tabular}

\begin{tabular}{lll}
\hline Fusarium & Fumonisins & $\begin{array}{l}\text { potentially carcinogenic by IARC (group 2B) } \\
\text { causes liver, renal, esophageal cancer and birth } \\
\text { defects }\end{array}$
\end{tabular}$\quad$ Apeh et al., 2021

defects

\begin{tabular}{llll}
\hline A. niger & Fumonisins & potentially carcinogenic & Haas et al., 2013
\end{tabular}

\begin{tabular}{|c|c|c|c|}
\hline $\begin{array}{l}\text { A. flavus } \\
\text { A. parasiticus }\end{array}$ & AFs & $\begin{array}{l}\text { poisonous carcinogens by IARC (group 1B) } \\
\text { mutagenic, carcinogenic, teratogenic and } \\
\text { immunosuppressive effects, causing chronic } \\
\text { diseases such as liver cancer }\end{array}$ & $\begin{array}{l}\text { Apeh et al., } 2021 \\
\text { Pakshir et al., } 2020\end{array}$ \\
\hline
\end{tabular}

\begin{tabular}{|c|c|c|c|}
\hline Fusarium & ZEA & $\begin{array}{l}\text { estrogenic potential } \\
\text { toxicity is associated with reproductive } \\
\text { problems } \\
\text { in tea the main problem is the high water- } \\
\text { solubility }\end{array}$ & $\begin{array}{l}\text { Marin et al., } 2013 \\
\text { Bogdanova et al., } 2020\end{array}$ \\
\hline \multirow[t]{2}{*}{ Fusarium } & DON & $\begin{array}{l}\text { induces immunosuppressive effects, cause } \\
\text { vomiting, temporary acute nausea, diarrhea, } \\
\text { abdominal pain, headache, dizziness and fever }\end{array}$ & $\begin{array}{l}\text { Bogdanova et al., } 2020 \\
\text { Sedova et al., } 2018\end{array}$ \\
\hline & & $\begin{array}{l}\text { in tea the main problem is the high water- } \\
\text { solubility and the potential extraction of DON } \\
\text { derivatives }\end{array}$ & Marin et al., 2013 \\
\hline
\end{tabular}

Source: Authors.

Contamination by mycotoxins is difficult to avoid, since there is a predisposition in all stages of processing and storage. However, adequate temperature and humidity conditions can assist in controlling contamination (Pakshir et al., 2020). Thus, attention is needed to quality control of tea production, as food safety depends on the level of contamination in the raw tea sample and the mycotoxin transfer and solubility capacity (Sedova et al., 2018). In addition, it is important to observe the maximum limits tolerated by legislation for contamination of mycotoxins in tea, as well as the daily consumption of this product must be respected, since the accumulation of contaminants in the body causes health problems in the long term (Pakshir et al., 2020).

$\mathrm{Pu}$-erh tea is more contaminated when compared to green, white and black tea, due to its production characteristics. The production of green tea for example, occurs in a reduced time because the fresh leaves are subjected to cooking immediately 
after harvest, which results in low favor of contamination in processing (Sedova et al., 2018, Pakshir et al., 2020). Also, when comparing samples of loose and instant Pu-erh tea (in tea bags), it is noticed that the loose product presents greater contamination, which can be justified by the exposure to contamination during bulk storage, while the packed tea has a small and compact surface area that limits contamination. In addition, the adherence of fungal spores to the filtering material of tea bags can be attributed (Haas et al., 2013).

\subsection{Sensory aspects}

Pu-erh tea is characterized by its distinctive and smooth aroma and dark red color (Wu et al., 2020). These sensory aspects are achieved after the fermentation of the tea, since the infusion of the raw material has an astringent flavor and yellow color. This change is related to the chemical metabolites present and the microbial activity (Zhao et al., 2019).

The formation of the aged and woody flavor of $\mathrm{Pu}$-erh tea is the result of the interaction between methoxy-phenolic compounds, alcohols, hydrocarbons, aldehydes, ketones and esters (Wang et al., 2020). The formation of methoxy-phenolic compounds (abundant in Pu-erh tea and high in content when compared to green, black, oolong and white teas) (Li et al., 2018) is related to the product of gallic acid methylation by methyltransferase enzymes and thermal degradation (Lv et al., 2013a). These compounds are responsible for the characteristic rancid aroma, used to differentiate $\mathrm{Pu}$-erh tea from the others. The sweet, floral and woody aroma is achieved by the presence of important aromatic components in tea: alcohols. However, these compounds are reduced during the fermentation process, due to their high volatility, which is a characteristic condition of $\mathrm{Pu}$ erh tea, different from other types of teas (Li et al., 2018).

Thus, it can be concluded that the phenolic compounds are metabolized and reduced during fermentation, giving the tea flavor a modification (Zhao et al., 2019). In addition to these compounds, tannase enzymes are also important for the sensory formation of Pu-erh tea, as they are able to act in the release of phenolic acids and hydrolysis of gallates, which reduces the astringency of pure tea and increases its mild flavor (Ma et al., 2021).

Inevitably most of these compounds are lost during the manufacture of instant tea, due to thermal processing, mainly in the stages of extraction and concentration, affecting the sensory quality of the final product (Wang et al., 2020). However, the aroma profile is not only determined by the process, but also by how the plant is grown. High quality teas have several parameters controlled from their planting to the final product and require specific processing steps (Feng et al., 2019).

Recently with the growing market for ready-to-eat products, $\mathrm{Pu}$-erh tea has been increasingly processed as instant tea. Although prepared by a succession of technologies, instant tea has a strong rancid note inherent in Pu-erh tea matured due to methoxy-benzene compounds. Some consumers accept the obsolete note, however, the vast majority of the population feels that the rancid note negatively affects the aroma of the drink (Zhang et al., 2019). There are methods available in the food industry that aim to reduce the loss of aroma compounds during the processing of the drink and recover the natural aroma of the raw material, such as membrane technology, condensation, adsorption and absorption, later concentrating this fraction and adding the compounds again of aroma to the final product (Wang et al., 2020).

Pang et al. (2019) prepared infusions from raw $\mathrm{Pu}$-erh tea and matured $\mathrm{Pu}$-erh tea to demonstrate differences in aroma notes using combined methodologies, these being gas chromatography-olfactometry, aroma extract dilution analysis, odor activity values and multivariate analysis. In raw tea 19 odor components were identified, with a complex variety of chemical classes with diverse odors and moderate odor intensities. The predominant aroma notes were floral, sweet and woody, derived from terpenic alcohols, terpenic ketones and phenolic compounds. In the matured tea 35 odor components were found, being dominated by structurally and organoleptically similar compounds with high potency, especially methoxybenzenes with a rancid and moldy smell.

Zhang et al. (2019) sought to elucidate chemicals that could mask the rancid note of Pu-erh tea products. In his work 
the sensory evaluation showed that the volatile extract of matured instant tea was dominated by strong rancid and sweet notes, noticeable green and floral notes, as well as a weak toasted note. It was reported that sweet notes (linalool), floral (linalool; transB-ionone; phenylethyl and indole alcohol) and gram (benzene acetaldehyde) managed to mask the old note. The higher the concentration of trans-B-ionone was added, the stronger the floral note intensity and the weaker the rancid note.

The evaluation of the Pu-erh tea producing leaves was carried out by Li et al. (2018) for 45 days. During this period there was a change in the color of the leaves and consequently in the tea liqueurs, reaching the desired characteristic color (dark red). In addition, the $\mathrm{pH}$ of the liquors also changed until reaching $\mathrm{pH} 6.58$ at the end of the analysis. Theabrownin, derived from phenolic compounds, is essential for the development of the characteristic color of Pu-erh tea as it is the main water-soluble polymer pigment (Lee; Foo, 2013).

The quality of food products, related to their chemical composition, physical properties, sensory aspects and microbiological contamination has a high influence on processing and storage (Di Rosa et al., 2017). The storage period of Puerh tea is a characteristic that deserves attention since its sensory aspects are favored with aging (Gao et al., 2016). However, although the concentrations of the chemical constituents in tea change over time, the quality of the tea stabilizes after a certain period (Xie et al., 2009).

The search for Pu-erh tea with high quality (aged) is intensified, which requires analysis of the products storage time, since they have higher prices when compared to freshly produced tea (Yang et al., 2021). Sensory techniques are applied to assess the effect of $\mathrm{Pu}$-erh tea storage time through trained judges who explore the five sense organs to assess perceived attributes (Zhou et al., 2020b) in addition to the use of conventional detection methods such as chromatography (Xie et al., 2009; Xu et al., 2019) and near-infrared spectroscopy (NIR) (Liu et al., 2018). Xu et al. (2019) studied studied the effect of the storage period in dry and cold, humid and hot environments through sensory analysis, determining that a large part of the flavoring compounds in Pu-erh tea leaves remain stable in dry and cold environments, claiming that this condition allows to maintain the original flavor of the product, when compared to those exposed to storage in humid and hot environments.

The development of artificial sensors to determine organoleptic characteristics of products through signals and pattern recognition has been constantly encouraged. The fusion of techniques can allow a more accurate and reliable determination on a product, reducing interference, errors and uncertainties (Borràs et al., 2015). The application of sensor devices such as noses and electronic tongues has positive responses regarding the aroma and flavor attributes of food products (Yang et al., 2021, Di Rosa et al., 2017, Gao et al., 2016). The electronic nose is able to identify simple and complex odors through technology that mimics the human olfactory system, through a fast and non-destructive operating system (Di Rosa et al., 2017). The electronic language employs a bionic detection technology in a non-destructive and quick result way. Its operating system is considered simple, sensitive and flexible to apply (Yang et al., 2021). Previous studies indicate that the technique can be applied to determine sensory characteristics because it provided uniform standards for the life of Pu-erh tea when compared to the results obtained in sensory analyzes with trained judges (Gao et al., 2016).

\subsection{Chemical compounds responsible for the bioactive profile}

Chemical studies of Pu-erh tea have detected the presence of polyphenols, theabrownins, flavonols, polysaccharides and alkaloids in small quantities (Long et al., 2020) in addition to amino acids such as phenylalanine, 1-theanine, glutamine and histidine (Huang et al., 2019b). As shown in Figure 1, the six types of teas produced by fresh leaves of Camellia sinensis are differentiated according to their processing. This processing combined with the cultivation conditions also differs the content of chemical components present in teas (Xu et al. 2018). Table 2 shows the main chemical compounds present in the different types of tea. 
Table 2 - Chemical compounds present in the different types of tea.

\begin{tabular}{|c|c|c|c|c|c|c|c|c|}
\hline $\begin{array}{c}\text { Chemical } \\
\text { compound } \\
(\mathrm{mg} / \mathrm{g})\end{array}$ & $\begin{array}{c}\text { Green } \\
\text { tea* }\end{array}$ & $\begin{array}{c}\text { Yellow } \\
\text { tea* }\end{array}$ & White tea* & $\begin{array}{c}\text { Oolong } \\
\text { tea* }\end{array}$ & Black tea* & $\begin{array}{c}\text { Pu-erh } \\
\text { tea* }\end{array}$ & $\begin{array}{c}\text { Matured } \\
\text { Pu-erh } \\
\text { tea** }\end{array}$ & $\begin{array}{l}\text { Raw Pu- } \\
\text { erh tea** }\end{array}$ \\
\hline Gallic acid & $2.01 \pm 0.92$ & $1.56 \pm 1.22$ & $2.33 \pm 1.20$ & $0.69 \pm 0.71$ & $4.4 \pm 1.47$ & $4.31 \pm 1.41$ & $4,96 \pm 0.17$ & $1.29 \pm 0.02$ \\
\hline Caffeine & $34.86 \pm 4.32$ & $33.32 \pm 7.1$ & $27.17 \pm 5.37$ & $19.67 \pm 2.95$ & $28.54 \pm 3.68$ & $33.94 \pm 3.68$ & $40.42 \pm 0.13$ & $34.51 \pm 1.17$ \\
\hline $\begin{array}{l}\text { Theobro } \\
\text { mine }\end{array}$ & $1.29 \pm 0.60$ & $0.91 \pm 0.45$ & $0.52 \pm 0.42$ & $0.37 \pm 0.13$ & $1.06 \pm 0.62$ & $1.67 \pm 0.49$ & $2.44 \pm 0.01$ & $1.77 \pm 0.02$ \\
\hline Catechin & $5.37 \pm 1.73$ & $4.37 \pm 1.63$ & $2.05 \pm 0.90$ & $1.01 \pm 0.28$ & $0.52 \pm 0.77$ & $7.43 \pm 1.46$ & ND & $7.22 \pm 0.47$ \\
\hline Epicatechin & $7.25 \pm 2.26$ & $8.14 \pm 3.48$ & $5.11 \pm 3.88$ & $7.00 \pm 1.24$ & $0.7 \pm 0.57$ & $12.3 \pm 3.86$ & $2.9 \pm 0.06$ & $14.81 \pm 0.24$ \\
\hline $\begin{array}{l}\text { Gallocate } \\
\text { chin }\end{array}$ & $4.02 \pm 2.19$ & $5.85 \pm 2.82$ & $2.54 \pm 1.45$ & $5.02 \pm 1.10$ & $0.14 \pm 0.30$ & $2.75 \pm 1.15$ & ND & $3.37 \pm 0.31$ \\
\hline $\begin{array}{l}\text { Epigallo } \\
\text { Catechin }\end{array}$ & $15.48 \pm 9.02$ & $\begin{array}{l}15.48 \pm 9.0 \\
2\end{array}$ & $9.29 \pm 4.68$ & $26.89 \pm 5.63$ & $0.78 \pm 0.58$ & $7.58 \pm 3.79$ & ND & $20.66 \pm 0.27$ \\
\hline $\begin{array}{l}\text { Gallocate } \\
\text { chin gallate }\end{array}$ & $\begin{array}{l}9.44 \pm \\
1.97\end{array}$ & $\begin{array}{l}9.17 \pm \\
3.01\end{array}$ & $\begin{array}{l}3.71 \pm \\
1.84\end{array}$ & $\begin{array}{l}2.70 \pm \\
0.74\end{array}$ & $\begin{array}{l}0.23 \pm \\
0.46\end{array}$ & $\begin{array}{l}3.87 \pm \\
1.24\end{array}$ & ND & $1.26 \pm 0.06$ \\
\hline $\begin{array}{l}\text { Epigallo } \\
\text { catechin } \\
\text { gallate }\end{array}$ & $54.06 \pm 6.83$ & $\begin{array}{l}53.96 \pm 8.6 \\
9\end{array}$ & $23.73 \pm 4.19$ & $27.44 \pm 3.66$ & $2.19 \pm 2.40$ & $28.19 \pm 6.50$ & ND & $\begin{array}{l}119.28 \pm 1.9 \\
9\end{array}$ \\
\hline $\begin{array}{l}\text { Epicatechin } \\
\text { gallate }\end{array}$ & $\begin{array}{l}17.10 \pm 3.3 \\
4\end{array}$ & $\begin{array}{l}16.23 \pm 7.0 \\
1\end{array}$ & $\begin{array}{l}8.12 \pm \\
3.05\end{array}$ & $5.09 \pm 1.64$ & $2.65 \pm 2.25$ & $30.60 \pm 4.18$ & $1.92 \pm 0.30$ & $47.11 \pm 0.94$ \\
\hline
\end{tabular}

Source: *Yi et al., 2015. **Long et al., 2020.

Evaluating green tea it is possible to verify that the content of epigallocatechin gallate $(54.06 \mathrm{mg} / \mathrm{g})$ and caffeine (34.86 $\mathrm{mg} / \mathrm{g}$ ) were higher than other types of tea, which is strongly related to the short processing period of green tea. Also, the similarity between the contents of green and yellow teas and the low content of the components in white tea can also be justified by processing.

As mentioned earlier, $\mathrm{Pu}$-erh tea is derived from green tea and needs an aging process during storage, which results in longer processing. However, tea storage does not affect theobromine (1.67 mg/g) and caffeine (33.94 mg/g) contents as these are almost equivalent to green tea $(1.29 \mathrm{mg} / \mathrm{g}$ and $34.86 \mathrm{mg} / \mathrm{g}$, respectively). The gallic acid content in Pu-erh tea (4.31 $\mathrm{mg} / \mathrm{g})$ was higher than that of green tea $(2.01 \mathrm{mg} / \mathrm{g})$. Epicatechin gallate is another component that stood out in Pu-erh tea because its content $(30.60 \mathrm{mg} / \mathrm{g})$ was superior to other types of tea, proving to be a unique component in the chemical composition of $\mathrm{Pu}$ erh tea (Yi et al., 2015).

The content of chemical components (including water extractable substances) present in raw tea is higher than green 
tea (Lv et al., 2013a). Tea leaves (black and green) contain about 2 to 5\% caffeine in water-extractable materials (Yang et al., 2011). The catechin content of Pu-erh tea (about $30 \%$ of the extractable solid weight of the dry infusion (Vuong et al., 2010)) it is lower than green tea, black tea and oolong tea, while the levels of caffeine, theabrownin and gallic acid increase during fermentation, while the catechin content decreases due to hydrolysis (Lee \& Foo, 2013; Armstrong et al., 2020).

Pu-erh tea has stood out due to its many health benefits, such as anti-hyperlipidemic, anti-diabetic, antioxidant, antitumor, antibacterial, anti-inflammatory and antiviral effects (Ma et al., 2021). The beneficial effects of bioactive compounds on human health are closely related to their digestion properties, as well as their bioaccessibility and bioavailability. Bioaccessibility includes the disintegration of large insoluble molecules in the food matrix into small soluble molecules that can be absorbed (Degirmencioglu et. al., 2020). The main chemical compounds present in Pu-erh tea are shown in Table 3, as well as their health benefits, reported according to controlled studies in vivo.

Reactive oxygen species (ROS) are essential for normal metabolism, acting as specific signalers under physiological conditions. However, its excess can damage the lipids, proteins and DNA of cells, resulting in a series of chronic diseases. The hepatoprotective and antioxidant effect of $\mathrm{Pu}$-erh tea has already been reported, which can be used to prevent and treat diseases related to oxidative stress (Cao et al., 2020). These bioactive properties of Pu-erh tea are mainly attributed to methylxanthines, which are purine alkaloids, widely present in coffee, teas, cocoa and others. The most popular methylxanthines are caffeine (1,3,7-trimethylxanthine), theophylline (1,3-dimethylxanthine) and theabrownin (3,7-dimethylxanthine) (Gong et al., 2012, Georgiev et al., 2019).

Zhou et al. (2019) reported that having caffeine (abundant methylxanthine) in Pu-erh tea is changing due to the participation of microorganisms found in solid state fermentation. The authors demonstrated that through aerobic fermentation of sydowii TET-2, $28.8 \mathrm{mg} / \mathrm{g}$ of caffeine were degraded, $93.18 \%$ of degraded caffeine was converted to theophylline and 24.60 $\mathrm{mg} / \mathrm{g}$ of theophylline was produced. Wu et al. (2007) attributed the caffeine content to the teas antimicrobial activity, demonstrating a biological action for Staphylococcus aureus and Bacillus subtilis. Escherichia coli was not significantly affected.

Theabrownin is one of the most active and abundant pigments in Pu-erh tea, with the equivalent of $24.62 \mathrm{mg} . \mathrm{L}^{-1} \mathrm{being}$ reported (Jankech et al., 2019). Theabrownin has been shown to alter the intestinal microbiota in mice and humans, predominantly supplying microorganisms associated with bile salt hydrolase (Huang et al., 2019a). In another study theabrownin was shown to effectively prevent elevation of triglycerides in rats fed diets high in fat, salt and sugar after three weeks of medium and high doses, with the higher dose also reducing insulin resistance (Wu et al., 2020). Georgiev et al. (2015) demonstrated that a fraction of methylxanthine extracted from Pu-erh tea had an antiproliferative effect in colon and breast carcinoma cell lines. In addition, the formation of theabrownin in the pile fermentation process is related to the increase in the dark color of the matured tea infusion (Long et al., 2020). 
Table 3 - Main compounds present in Pu-erh tea and this health benefits.

\begin{tabular}{|c|c|c|}
\hline Compound present in Pu-erh tea & Benefits & Reference \\
\hline Caffeine & $\begin{array}{l}\text { inhibits lung and skin tumorigenesis in rats } \\
\text { and mice } \\
\text { reduces fatty tissue in mice } \\
\text { inhibits progression of pulmonary } \\
\text { adenomas in mice }\end{array}$ & Yang et al., 2011 \\
\hline \multirow[t]{2}{*}{ Theobromine } & $\begin{array}{c}\text { attenuate hypercholesterolemia via } \\
\text { modulation of gut microbiota and bile acid } \\
\text { metabolismbioactive }\end{array}$ & Ma et al., 2021 \\
\hline & $\begin{array}{l}\text { prevents visceral fat accumulation and } \\
\text { improves hyperlipidemia in rats }\end{array}$ & Lee and Foo, 2013 \\
\hline Catechin & $\begin{array}{l}\text { essential to sensory quality of tea } \\
\text { reduces the incidence of coronary heart } \\
\text { disease, diabetes and cancer } \\
\text { increases the conversion of cholesterol to } \\
\text { bile acids and reduces the cholesterol } \\
\text { content in the liver }\end{array}$ & $\begin{array}{l}\text { Ma et al., } 2021 \\
\text { Lee and Foo, } 2013\end{array}$ \\
\hline Epigallocatechin gallate & $\begin{array}{l}\text { inhibits tumorigenesis in animal models } \\
\text { (rats, mice and hamsters) for different } \\
\text { organs, such as stomach, lung, small } \\
\text { intestine, oral cavity, esophagus, colon, } \\
\text { skin, liver, bladder, prostate and mammary } \\
\text { glands }\end{array}$ & Yang et al., 2011 \\
\hline Gallic acid & $\begin{array}{l}\text { antimicrobial effects, in the digestive tract, } \\
\text { liver, cardiovascular, nervous systems and } \\
\text { reproductive health and its } \\
\text { chemopreventive activity on cancer }\end{array}$ & Ge et al. 2019 \\
\hline
\end{tabular}

Source: Authors.

The catechin content in Pu-erh tea is reported mainly through the epigallocatechin gallate form, considered to be the most abundant and active form of catechins. However, the other catechins in tea (epigallocatechin, epicatechin gallate, epicatechin, galocatechin and catechin) are able to prevent the resorption of bile acids, reduce the cholesterol content in the liver and reduce the absorption of triacylglycerol by inhibiting pancreatic lipase (Yang et al., 2011).

The phenolic acid content in Pu-erh tea (raw and ripened) was assessed by Ge et al. (2019) indicating the presence of gallic acid in raw tea. This bioactive compound is characterized by its antioxidant, antibacterial, anti-tumor and anti-obesity aspects. The presence of vanillic acid, protocatechuic acid, dihydroxy-methoxybenzoic acid, salicylic acid, 3-hydroxybenzoic acid and isomers of dimethoxybenzoic acid were found in the matured tea, which stand out for their antimicrobial effects, in the digestive tract, liver, cardiovascular, nervous systems and reproductive health and its chemopreventive activity on cancer. In addition an increase in the content of phenolic acids can be seen after the fermentation process of Pu-erh tea, when compared to raw tea, conferring a greater absorption of bioactive compounds.

Only $20-30 \%$ of the polyphenols in tea are absorbed by the small intestine, the other components undergo microbial degradation of the colon in the gastrointestinal tract, forming new metabolites that modulate the intestinal microbiota (Xia et al., 2019). The intestinal microbiota plays a vital role in promoting health, including providing nutrients, preventing colonization of pathogens and maintaining mucous immunity. The adoption of dietary patterns has an influence on the diversity and abundance 
of the intestinal microbiota, affecting the health of the host. In an in vivo study Pu-erh tea was shown to stimulate the abundance of Alistipes and Odoribacter in the intestinal microbiota of rats. This increase was associated with diets rich in polyphenols. Byproducts of bacterial metabolism play a vital role in maintaining and maintaining colon metabolism (Zheng et al., 2020).

\section{Conclusion}

Originated in China, Pu-erh tea is considered an ancestral product that achieves its own characteristics of woody flavor, smooth aroma and dark red color through the fermentation process, due to the formation of volatile compounds, microbial activity and metabolites chemicals present in tea. The expansion of this product on the market has led to a concern with its processing, due to the need to adapt the process while maintaining its characteristic sensory aspects and respecting consumer preference. In addition, attention is required to the quality control of the production of $\mathrm{Pu}$-erh tea, aiming at food safety due to the mycotoxin production capacity of the microorganisms involved in the processing The health benefits of consuming Pu-erh tea (antihyperlipidemic, anti-diabetic, antioxidant, anti-tumor, antibacterial, anti-inflammatory and antiviral effects) are related to the bioactive compounds present, highlighting the polyphenols, theabrownins, flavonols, polysaccharides, alkaloids and amino acids, that relate to the properties of digestion, bioaccessibility and bioavailability. In this sense, the effective control of production conditions results in health benefits that outweigh the risks. Therefore, further studies need to be performed to evaluate the influence of processing of Pu-erh tea in its characteristic sensory aspects, aiming at food safety.

\section{Acknowledgments}

The authors are pleased to acknowledge the Coordination of Improvement of Higher Education Personnel (CAPES) Foundation - finance code 001 for the financial support.

\section{References}

Apeh, D. O., Mark, O., Onoja, V. O., Awotunde, M., Ojo, T., Christopher, P., \& Makun, H. A. (2021). Hydrogen cyanide and mycotoxins: Their incidence and dietary exposure from cassava products in Anyigba, Nigeria. Food Control, 121. 107663. 10.1016/j.foodcont.2020.107663

Armstrong, L., do Carmo, M. A. V., Wu, Y., Esmerino, L. A., Azevedo, L., Zhang, L., \& Granato, D. (2020). Optimizing the extraction of bioactive compounds from pu-erh tea (Camellia sinensis var. assamica) and evaluation of antioxidant, cytotoxic, antimicrobial, antihemolytic, and inhibition of $\alpha$-amylase and $\alpha$ glucosidase activities. Food Res. Int., 137, 109430. 10.1016/j.foodres.2020.109430

Bogdanova, E., Pugajeva, I., Reinholds I., \& Bartkevics, V. (2020). Two-dimensional liquid chromatography - high resolution mass spectrometry method for simultaneous monitoring of 70 regulated and emerging mycotoxins in Pu-erh tea. J. Chromatogr. A., 1622, 461145. 10.1016/j.chroma.2020.461145

Borràs, E., Ferré, J., Boqué, R., Mestres, M., Aceña, L., \& Busto, O. (2015). Data fusion methodologies for food and beverage authentication and quality assessment - A review. Anal. Chim. Acta., 891, 1-14. 10.1016/j.aca.2015.04.042

Cao, S. Y., Li, B. Y., Gan, R.Y., Mao, Q. Q., Wang, Y. F., Shang, A., Meng, J. M., Xu, X. Y., Wei, X. L., \& Li, H. B. (2020). The In Vivo Antioxidant and Hepatoprotective Actions of Selected Chinese Teas. Foods, 9, 262. 10.3390/foods9030262

Cao, X., Liu, M., Hu, Y., Xue, Q., Yao, F., Sun, J., Sun L., \& Liu. Y. (2021). Systemic characteristics of biomarkers and differential metabolites of raw and ripened pu-erh teas by chemical methods combined with a UPLC-QQQ-MS-based metabolomic approach. LWT - Food Sci. Technol., 136, 110316. 10.1016/j.lwt.2020.110316

Choi, S. H., Kim, I. D., Dhungana S. K., \& Kim, D. G. (2018). Comparison of Quality Characteristic and Antioxidant Potential of Cultivated Pu-erh and Gushu Pu-erh Tea Extracts at Two Temperatures. J. Pure Appl. Microbiol., 12, 1155-1161. 10.22207/JPAM.12.3.14

Degirmencioglu, N., Yildiz, E., Sahan, Y., Güldas, M., \& Gürbüz, O. (2020). Impact of tea leaves types on antioxidant properties and bioaccessibility of kombucha. J. Food Sci. Technol., 10.1007/s13197-020-04741-7

Di Rosa, A. R., Leone, F., Cheli, F., \& Chiofalo, V. (2017). Fusion of electronic nose, electronic tongue and computer vision for animal source food authentication and quality assessment - A review. J. Food Eng., 210, 62-75. 10.1016/j.jfoodeng.2017.04.024

Fan, J. P., Fan, C., Dong, W. M., Gao, B.,Yuan, W., \& Gong, J. S. (2013). Free radical scavenging and anti-oxidative activities of an ethanol-soluble pigment extract prepared from fermented Zijuan Pu-erh tea. Food Chem. Toxicol., 59, 527-533. 10.1016/j.fct.2013.06.047 
Feng, Z., Li, Y., Wang, Y., Zhang, L., Wan, X., \& Yang, X. (2019). Tea aroma formation from six model manufacturing processes. Food Chem., $285,347-354$. 10.1016/j.foodchem.2019.01.174

Ferreira, C. D., Lang, G. H., Lindemann, I. S., Timm, N. S., Hoffmann, J. F., Ziegler, V., \& de Oliveira, M. (2021). Postharvest UV-C irradiation for fungal control and reduction of mycotoxins in brown, black, and red rice during long-term storage. Food Chem., 339, 127810. 10.1016/j.foodchem.2020.127810

Gao, L., Bian, M., Mi, R., Hu, X., \& Wu, J. (2016). Quality identification and evaluation of Pu-erh teas of different grade levels and various ages through sensory evaluation and instrumental analysis. Int. J. Food Sci. Technol., 51, 1338-1348. 10.1111/ijfs.13103

Georgiev, K. D., Ilieva, M. R., Stoeva, S., \& Zhelev, I. (2019). Isolation, analysis and in vitro assessment of CYP3A4 inhibition by methylxanthines extracted from Pu-erh and Bancha tea leaves. Sci. Rep., 9, 13941. 10.1038/s41598-019-50468-7

Georgiev, K., Iliev, I., \& Jelev, I. (2015). Evaluation of antitumor effect of methylxanthine fraction isolated from Pu-erh tea. World J. Pharm. Res., 4, 22362242 .

Ge, Y., Bian, X., Sun, B., Zhao, M., Ma, Y.,Tang, Y., Li, N., \& Wu, J. L. (2019). Dynamic Profiling of Phenolic Acids during Pu-erh Tea Fermentation Using Derivatization Liquid Chromatography-Mass Spectrometry Approach. J. Agric. Food Chem., 67, 4568-4577. 10.1021/acs.jafc.9b00789

Gong, J. S., Tang, C., \& Peng, C. X. (2012). Characterization of the chemical differences between solvent extracts from Pu-erh tea and Dian Hong black tea by CP-Py-GC/MS. J. Anal. Appl. Pyrolysis., 95, 189-197. 10.1016/j.jaap.2012.02.006

Haas, D., Pfeifer, B., Reiterich, C., Partenheimer, R., Reck, B., \& Buzina, W. (2013). Identification and quantification of fungi and mycotoxins from Pu-erh tea. Int. J. Food Microbiol., 166, 316-322. 10.1016/j.ijfoodmicro.2013.07.024

Huang, F., Zheng, X., Ma, X., Jiang, R., Zhou, W., Zhou, S., Zhang, Y., Lei, S., Wang, S., Kuang, J., Han, X., Wei, M., You, Y., Li, M., Li, Y., Liang, D., Liu, J., Chen, T., Yan, C., Wei, R., Rajani, C., Shen, C., Xie, G., Bian, Z., Li, H., Zhao A., \& Jia, W. (2019a). Theabrownin from Pu-erh tea attenuates hypercholesterolemia via modulation of gut microbiota and bile acid metabolism. Nat. Commun., 10, 4971. 10.1038/s41467-019-12896-x

Huang, Y., Wang T., Fillet, M., Crommen, J., \& Jiang, Z. (2019b). Simultaneous determination of amino acids in different teas using supercritical fluid chromatography coupled with single quadrupole mass spectrometry. J. Pharm. Anal., 9, 254-258. 10.1016/j.jpha.2019.05.001

Jankech, T., Maliarová, M., \& Martinka, N. (2019). Determination of methylxanthines in tea samples by HPLC method. Nova Biotechnol. Chim., 18, 124-132. 10.2478/nbec-2019-0015

Lee, L. K., \& Foo, K. Y. (2013). Recent advances on the beneficial use and health implications of Pu-Erh tea. Food Res. Int., 53, 619-628 10.1016/j.foodres.2013.02.036

Liu, Z., Xie, H. I., Chen, L., \& Huang, J. H. (2018). An Improved Weighted Partial Least Squares Method Coupled with Near Infrared Spectroscopy for Rapid Determination of Multiple Components and Anti-Oxidant Activity of Pu-Erh Tea. Molecules, 23, 1058. 10.3390/molecules23051058

Li, Z., Feng, C., Luo, X., Yao, H., Zhang, D., \& Zhand, T. (2018). Revealing the influence of microbiota on the quality of Pu-erh tea during fermentation process by shotgun metagenomic and metabolomic analysis. Food Microbiol., 76, 405-415. 10.1016/j.fm.2018.07.001

Long, P., Wen, M., Granato, D., Zhou, J., Wu, Y., Hou, Y., \& Zhang, L. (2020). Untargeted and targeted metabolomics reveal the chemical characteristic of puerh tea (Camellia assamica) during pile-fermentation. Food Chem., 311, 125895. 10.1016/j.foodchem.2019.125895

Lv, H. P., Zhang, Y. J., Lin, Z., \& Liang, Y. R. (2013a). Processing and chemical constituents of Pu-erh tea: A review. Food Res. Int., 53, 608-618. 10.1016/j.foodres.2013.02.043

Lv, H. P., Lin, Z., Tan, J. F., \& Guo, L. (2013b). Contents of fluoride, lead, copper, chromium, arsenic and cadmium in Chinese Pu-erh tea. Food Res. Int., 53, 938-944. 10.1016/j.foodres.2012.06.014

Marin, S., Ramos, A. J., Cano-sancho, G., \& Sanchis, V. (2013). Mycotoxins: Occurrence, toxicology, and exposure assessment. Food Chem Toxicol., 60, 218237. 10.1016/j.fct.2013.07.047

Ma, Y., Ling, T. J., Su, X. Q., Jiang, B., Nian, B., Chen, L. J., Liu, M. I., Zhang, Z. Y., Wang, D. P., Mu, Y. Y., Jiao, W. W., Liu, Q. T., Pan, Y. H., \& Zhao, M. (2021). Integrated proteomics and metabolomics analysis of tea leaves fermented by Aspergillus niger, Aspergillus tamarii and Aspergillus fumigatus. Food Chem., 334, 127560. 10.1016/j.foodchem.2020.127560

Pakshir, K., Mirshekari, Z., Nouraei, H., Zareshahrabadi, Z., Zomorodian, K., Khodadadi, H., \& Hadaegh, A. (2020). Mycotoxins Detection and Fungal Contamination in Black and Green Tea by HPLC-Based Method. J. Toxicol., 7 p. 10.1155/2020/2456210

Pang, X., Yu, W., Cao, C., Yuan X., Qiu, J., Kong, F., \& Wu, J. (2019). Comparison of Potent Odorants in Raw and Ripened Pu-Erh Tea Infusions Based on Odor Activity Value Calculation and Multivariate Analysis: Understanding the Role of Pile Fermentation. J. Agric. Food Chem., 67, 13139-13149. 10.1021/acs.jafc.9b05321

Roda, G., Marinello, C., Grassi, A., Picozzi, C., Aldini, G., Carini, M., \& Regazzoni, L. (2019). Ripe and Raw Pu-Erh Tea: LC-MS Profiling, Antioxidant Capacity and Enzyme Inhibition Activities of Aqueous and Hydro-Alcoholic Extracts. Molecules, 24, 473. 10.3390/molecules24030473

Sedova, I., Kiseleva, M., \& Tutelyan, V. (2018). Mycotoxins in Tea: Occurrence, Methods of Determination and Risk Evaluation. Toxins, $10,444$. $10.3390 /$ toxins 10110444

Shao, L., Wang, G., Guo, M.,Yang, L., Jiang, D., Li, R., \& Zhu, J. (2020). Determination of 9,10-anthraquinone in tea consumed in Shandong Province of China. Chem. Pap., 74, 4453-4460. 10.1007/s11696-020-01254-7 
Vuong, Q. V., Golding, J. B., Nguyen, M., \& Roach, P. D. (2010). Extraction and isolation of catechins from tea. J. Sep. Sci., 33, $3415-3428$.

Wang, C., He, Z., Zhang, C., Du, L., Xiao, D., \& Xu, Y. (2020). Sensory and instrumental analysis-guided exploration of odor-active compounds recovery with oil during the water-boiling extraction of Pu-erh tea. Food Res. Int., 134, 109243. 10.1016/j.foodres.2020.109243

Wu, E., Zhang, T., Tan, C., Peng, C., Chisti, Y., Wang, Q., \& Gong, J. (2020). Theabrownin from Pu-erh tea together with swinging exercise synergistically ameliorates obesity and insulin resistance in rats. Eur. J. Nutr., 59, 1937-1950. 10.1007/s00394-019-02044-y

Wu, S. C., Yen, G. C., Wang, B. S., Chiu, C. K., Yen, W. J., Chang, L. W., \& Duh, P. D. (2007). Antimutagenic and antimicrobial activities of pu-erh tea. LWT - Food Sci. Technol., 40, 506-512 10.1016/j.1wt.2005.11.008.

Xia, Y., Tan, D., Akbary, R., Kong, J., Seviour, R., \& Kong, Y. (2019). Aqueous raw and ripe Pu-erh tea extracts alleviate obesity and alter cecal microbiota composition and function in diet-induced obese rats. Appl. Microbiol. Biotechnol., 103, 1823-1835. 10.1007/s00253-018-09581-2

Xie, G., Ye, M., Wang, Y., Ni, Y., Su, M., Huang, H., Qiu, M., Zhao, A., Zheng, X., Chen, T., \& Jia, W. (2009). Characterization of Pu-erh Tea Using Chemical and Metabolic Profiling Approaches. J. Agric. Food Chem., 57, 3046-3054. 10.1021/jf804000y

Xue, J., Yang, L., Yang, Y., Yan, J., Ye, Y., Hu, C., \& Meng, Y. (2020). Contrasting microbiomes of raw and ripened Pu-erh tea associated with distinct chemical profiles. LWT - Food Sci. Technol., 124, 109147. 10.1016/j.lwt.2020.109147

Xu, J., Wang, M., Zhao, J., Wang,Y. H., Tang, Q., \& Khan, I. A. (2018). Yellow tea (Camellia sinensis L.), a promising Chinese tea: Processing, chemical constituents and health benefits. Food Res. Int., 107, 567-577. 10.1016/j.foodres.2018.01.063

Xu, S., Wang, J. J., Wei, Y., Deng, W. W., Wan,X., Bao, G. H., Xie, Z., Ling, T. J., \& Ning, J. (2019). Metabolomics Based on UHPLC-Orbitrap-MS and Global Natural Product Social Molecular Networking Reveals Effects of Time Scale and Environment of Storage on the Metabolites and Taste Quality of Raw Pu-erh Tea. J. Agric. Food Chem., 67, 12084-12093. 10.1021/acs.jafc.9b05314

Yang, C.S., Wang, H., Li, G. X., Yang, Z., Guan, F., \& Jin, H. (2011). Cancer prevention by tea: Evidence from laboratory studies. Pharmacol. Res., 64, 113122. 10.1016/j.phrs.2011.03.001

Yang, Z., Miao, N., Zhang, X., Li, Q., Wang, Z., Li, C., Sun. X., \& Lan, Y. (2021). Employment of an electronic tongue combined with deep learning and transfer learning for discriminating the storage time of Pu-erh tea. Food Control, 121, 107608. 10.1016/j.foodcont.2020.107608

Yi, T., Zhu, L., Peng, W. L., He, X. C., Chen, H. L., Li, J., Yu, T., Lian, Z. T., Zhao, Z. Z., \& Chen, H. B. (2015). Comparison of ten major constituents in seven types of processed tea using HPLC-DAD-MS followed by principal component and hierarchical cluster analysis. LWT - Food Sci. Technol., 62, 194-201. 10.1016/j.lwt.2015.01.003

Zhang, T., Ni, H., Qiu, X. J., Li, T., Zhang, L. Z., Li, L. J., Jiang, Z. D., Li, Q. B., Chen. F., \& Zheng, F. P. (2019). Suppressive Interaction Approach for Masking Stale Note of Instant Ripened Pu-Erh Tea Products. Molecules, 24, 4473. 10.3390/molecules24244473

Zhao, M., Su, X. Q., Nian, B., Chen, L. J., Zhang, D. L., Duan, S. M., Wang, L. Y., Shi, X. Y., Jiang, B., Jiang, W. W., Lv, C. Y.,Wang, D. P., Shi, Y., Xiao, Y., Wu, J. L., Pa, Y. H., \& Ma, Y. (2019). Integrated Meta-omics Approaches To Understand the Microbiome of Spontaneous Fermentation of Traditional Chinese Pu-erh Tea. Am. Soc. Microbiol., 4, e00680-19. 10.1128/mSystems.00680-19

Zhao, Z. J., Tong, H. R., Zhou, Wang E. X., \& Liu, Q. J. (2010). Fungal colonization of Pu-erh tea in Yunnan. J. Food Saf., 30, 769-784. 10.1111/j.17454565.2010. 00240.x

Zheng, Y., Zeng, X., Chen, T., Peng, W., \& Su, W. (2020). Chemical Profile, Antioxidative, and Gut Microbiota Modulatory Properties of Ganpu Tea: A Derivative of Pu-erh Tea. Nutrients, 12, 224. 10.3390/nu12010224

Zhou, B., Ma, C., Ren, X., Xia, T., Li, X., \& Wu, Y. (2019). Production of theophylline via aerobic fermentation of pu-erh tea using tea-derived fungi. BMC Microbiol, 19, 261. 10.1186/s12866-019-1640-2

Zhou, B., Ma, C., Wu, T., Xu, C., Wang, J., \& Xia, T. (2020a). Classification of raw Pu-erh teas with different storage time based on characteristic compounds and effect of storage environment. LWT-Food Sci. Technol., 133, 109914. 10.1016/j.1wt.2020.109914

Zhou, B., Ma, C., Ren, X., Xia, T., Zheng, C., \& Liu, X. (2020b). Correlation analysis between filamentous fungi and chemical compositions in a pu-erh type tea after a long-term storage. Food Sci. Nutr., 8, 2501-2511. 10.1002/fsn3.1543 